\title{
High-dispersion infrared spectroscopic observations of comet 8P/Tuttle with VLT/CRIRES ${ }^{\star}$
}

\author{
H. Kobayashi ${ }^{1}$, D. Bockelée-Morvan ${ }^{2}$, H. Kawakita ${ }^{1}$, N. Dello Russo ${ }^{3}$, E. Jehin ${ }^{4}$, J. Manfroid ${ }^{4}$, A. Smette ${ }^{5}$,

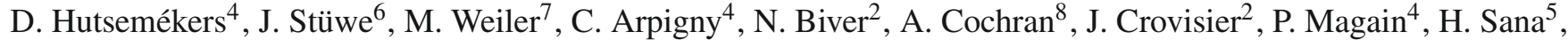 \\ R. Schulz ${ }^{9}$, R. J. Vervack ${ }^{3}$, H. Weaver ${ }^{3}$, and J.-M. Zucconi ${ }^{10, \star \star}$ \\ 1 Department of Physics, Faculty of Science, Kyoto Sangyo University, Motoyama, Kamigamo, Kita-ku, Kyoto, Japan \\ e-mail: h_kobayashi@cc.kyoto-su.ac.jp \\ 2 LESIA, Observatoire de Paris, 5 place Jules Janssen, 92195 Meudon, France \\ 3 Space Department, The Johns Hopkins University Applied Physics Laboratory, 11100 Johns Hopkins Road, Laurel, \\ MD 20723-6099, USA \\ 4 Institut d'Astrophysique et de Géophysique, Sart-Tilman, 4000 Liège, Belgium \\ 5 European Southern Observatory, Alonso de Cordova 3107, Vitacura, Santiago 19, Chile \\ 6 Leiden Observatory, 2300 RA Leiden, The Netherlands \\ 7 GEPI, Observatoire de Paris, 5 place Jules Janssen, 92195 Meudon, France \\ 8 Department of Astronomy and McDonald Observatory, University of Texas at Austin, Austin, USA \\ 9 ESA/RSSD, ESTEC, PO Box 299, 2200 AG Noordwijk, The Netherlands \\ 10 Observatoire de Besançon, 25010 Besançon Cedex, France
}

Received 13 May 2009 / Accepted 13 October 2009

\begin{abstract}
We report on the composition of the Halley-family comet (HFC) 8P/Tuttle investigated with high-dispersion near-infrared spectroscopic observations. The observations were carried out at the ESO VLT (Very Large Telescope) with the CRIRES instrument as part of a multi-wavelength observation campaign of 8P/Tuttle performed in late January and early February 2008. Radar observations suggested that $8 \mathrm{P} /$ Tuttle is a contact binary, and it was proposed that these components might be heterogeneous in chemistry. We determined mixing ratios of organic volatiles with respect to $\mathrm{H}_{2} \mathrm{O}$ and found that mixing ratios were consistent with previous near infrared spectroscopic observations obtained in late December 2007 and in late January 2008. It has been suggested that because $8 \mathrm{P} /$ Tuttle is a contact binary, it might be chemically heterogeneous. However, we find no evidence for chemical heterogeneity within the nucleus of $8 \mathrm{P} /$ Tuttle. We also compared the mixing ratios of organic molecules in $8 \mathrm{P} /$ Tuttle with those of both other HFCs and long period comets (LPCs) and found that $\mathrm{HCN}, \mathrm{C}_{2} \mathrm{H}_{2}$, and $\mathrm{C}_{2} \mathrm{H}_{6}$ are depleted whereas $\mathrm{CH}_{4}$ and $\mathrm{CH}_{3} \mathrm{OH}$ have normal abundances. This may indicate that $8 \mathrm{P} /$ Tuttle was formed in a different region of the early solar nebula than other HFCs and LPCs. We estimated the conversion efficiency from $\mathrm{C}_{2} \mathrm{H}_{2}$ to $\mathrm{C}_{2} \mathrm{H}_{6}$ by hydrogen addition reactions on cold grains by employing the $\mathrm{C}_{2} \mathrm{H}_{6} /\left(\mathrm{C}_{2} \mathrm{H}_{6}+\mathrm{C}_{2} \mathrm{H}_{2}\right)$ ratio. The $\mathrm{C}_{2} \mathrm{H}_{6} /\left(\mathrm{C}_{2} \mathrm{H}_{6}+\mathrm{C}_{2} \mathrm{H}_{2}\right)$ ratio in $8 \mathrm{P} /$ Tuttle is consistent with the ratios found in other HFCs and LPCs within the error bars. We also discuss the source of $\mathrm{C}_{2}$ and $\mathrm{CN}$ based on our observations and conclude that the abundances of $\mathrm{C}_{2} \mathrm{H}_{2}$ and $\mathrm{C}_{2} \mathrm{H}_{6}$ are insufficient to explain the $\mathrm{C}_{2}$ abundances in comet $8 \mathrm{P} /$ Tuttle and that the abundance of $\mathrm{HCN}$ is insufficient to explain the $\mathrm{CN}$ abundances in the comet, so at least one additional parent is needed for each species, as pointed out in previous study.
\end{abstract}

Key words. comets: individual: 8P/Tuttle - planets and satellites: formation - Kuiper belt: general

\section{Introduction}

Comets are remnants of planetesimals formed in the early solar nebula. Their nuclei consist of volatile ices and dust grains and are thought to preserve primordial information such as temperature, degree of ionization, and chemistry. Comet composition may also provide clues about the dynamical evolution of planetesimals in the early solar system. Comets are dynamically classified by their Tisserand invariants with respect to Jupiter $\left(T_{\mathrm{J}}\right)$ : ecliptic comets $\left(T_{\mathrm{J}}>2\right.$, here we call them Jupiter family comets: JFCs) and nearly isotropic comets (NICs, $T_{\mathrm{J}}<2$ ) (Levison 1996). The NICs are further divided into two sub-classes: long period comets (LPCs, semi-major axis $(a)>40 \mathrm{AU}$ ) and Halley-family comets (HFCs, $a<40$ AU) (Levison 1996). The

^ Based on observations collected at the European Southern Observatory, Paranal, Chile (ESO Prog. 080.C-0615 and 280.C-5053).

$\star \star$ We regret to note the death of Dr. J. -M. Zucconi in 2009 May. dynamical origin of LPCs is thought to be the Oort cloud whereas JFCs are thought to originate in the classical Kuiper Belt and/or the scattered disk. The dynamical origin of HFCs is unclear and still under debate. They were injected either into the inner part of the Oort cloud or into the outer part of the scattered disk (Duncan, 2008).

HFCs have long been studied by spectrophotometry at optical wavelengths (e.g., A'Hearn et al. 1995). Optical spectroscopic observations allow us to observe the daughter species produced by photo-dissociation of parent (or grand-parent, etc.) species in the coma, e.g., $\mathrm{H}_{2} \mathrm{O}, \mathrm{HCN}$, and $\mathrm{C}_{2} \mathrm{H}_{2}$. Strong vibrational and/or rotational transitions of parent species are observable in the near infrared and radio regions of the spectrum (Bockelée-Morvan et al. 2004). As an example, Biver et al. (2002) and Crovisier et al. (2008) reported the mixing ratios of parent molecules in four HFCs observed at radio wavelengths. In the near infrared region, DiSanti \& Mumma (2008) summarized 
the mixing ratios of organic volatiles for two HFCs (153P/IkeyaZhang and 1P/Halley). Because of the small sample size, the chemistry of HFCs as a group is still not well-characterized.

Our scientific goal in the present work is to determine the relative production rates (mixing ratios) of organic volatiles in the HFC 8P/Tuttle by using high-dispersion spectroscopic observations in the near infrared spectral region. This project is part of a multi-wavelength study of 8P/Tuttle performed at the VLT (see Sect. 2). In the present paper, we will focus on observations taken with the CRIRES spectrometer. In Sect. 3, we will derive rotatinal temperatures and mixing ratios of organic volatiles in comet 8P/Tuttle. Bonev et al. (2008) and Boehnhardt et al. (2008) also reported mixing ratios of organic volatiles in comet $8 \mathrm{P} /$ Tuttle from near infrared high-dispersion spectroscopic observations. We compare thses results with ours in Sect. 4.

\section{Observations and data reduction}

Comet 8P/Tuttle was observed at multiple wavelengths using the ESO Very Large Telescope (VLT) located on Cerro Paranal in Chile. We observed this comet using UVES (Unit Telescope (UT) 2) on January 16, 28 and February 4, 2008, and FORS1 (UT2) and CRIRES (UT1), on January 28 and February 4, 2008. The V-band magnitudes of $8 \mathrm{P} /$ Tuttle were $7-8$ in this period. Here we focus on the near-infrared high dispersion spectroscopic observations with CRIRES. The CRIRES (CRyogenic highresolution InfraRed Echelle Spectrograph, Käufl et al. 2004) can achieve high resolving power $(\lambda / \Delta \lambda \sim 100000$ with the slit width of $0.2^{\prime \prime}$, i.e., $\Delta \lambda \sim 0.03 \mathrm{~nm}$ at $3000 \mathrm{~nm}$ ). CRIRES records a single echelle order on a mosaic of four InSb Aladdin III arrays with $27 \mu \mathrm{m}$ pixels. The mechanical gaps between 2 arrays correspond to about 280 pixels. The telescope was nodded between two different positions (A and B, separated by $15^{\prime \prime}$ ) in a dithering sequence of ABBA (position A (image "A1") $\rightarrow$ position B (image "B1") $\rightarrow$ position B (image "B2") $\rightarrow$ position A (image "A2")) with jittering (small random offset). We used two different wavelength settings on Jan. 28 (a setting \#1 for $\mathrm{H}_{2} \mathrm{O}$, and a setting \#2 for $\mathrm{HCN}$ and $\mathrm{C}_{2} \mathrm{H}_{2}$ ) and 3 settings on Feb. 4 (a setting $\# 1^{\prime}$ for $\mathrm{H}_{2} \mathrm{O}$, a setting \#3 for $\mathrm{CH}_{4}$ and $\mathrm{C}_{2} \mathrm{H}_{6}$, and a setting \#4 for $\mathrm{CH}_{3} \mathrm{OH}$ ). The wavelength coverage of each setting is given in Table 1 . The slit widths were $0.2^{\prime \prime}$ and $1.0^{\prime \prime}$ for the comet and a flux standard star (30 Mon; spectral type: A0V), respectively. The slit length was $31^{\prime \prime}$ for both cases.

Data were processed using the Image Reduction and Analysis Facility (IRAF) software package distributed by NOAO. For each sequence of ABBA, we calculated (A1 - B1 $-\mathrm{B} 2+\mathrm{A} 2$ ) to remove sky background emission. Wavelength calibration and re-sampling of spectra were performed by comparing measured sky background emission lines and modeled atmospheric radiance spectra. Since we also employed "jittering" along the slit (random small offsets at both A and B positions to avoid severe defects on the arrays), we spatially registered the spectra before combining them into a single two-dimensional spectrum (Fig. 1). We extracted a one-dimensional (1-D) spectrum from an aperture $\left(0.2^{\prime \prime} \times \sim 0.8^{\prime \prime}\right)$ centered on the nucleus.

The 1-D spectrum was flux calibrated as follows. The spectra of the standard star were compared with the synthesized stellar spectra (combined with the telluric absorption at a given airmass by the LBLRTM code, Clough et al. 1995) to evaluate the efficiency of both the telescope and the CRIRES instrument. The flux loss of the standard star at the slit (1.0" slit width) was estimated from the brightness spatial profile of the star along the slit. Since the spatial profile has a concentrated core and a wing part, we modeled the spatial profile as a linear combination of
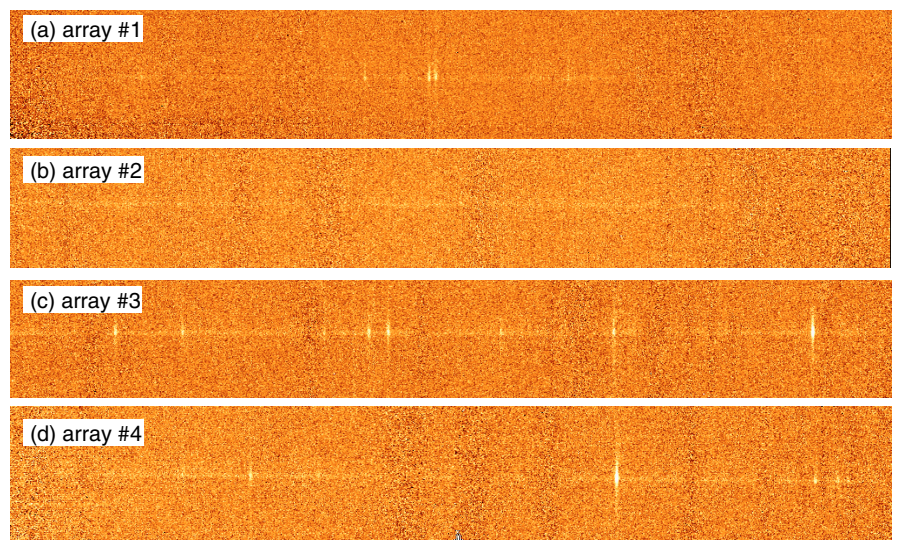

Fig. 1. Examples of two-dimensional spectra of comet 8P/Tuttle. Spectra shown in a)-d) were taken simultaneously by the four CRIRES arrays on January 28, 2008 using setting \#1 (Table 1).
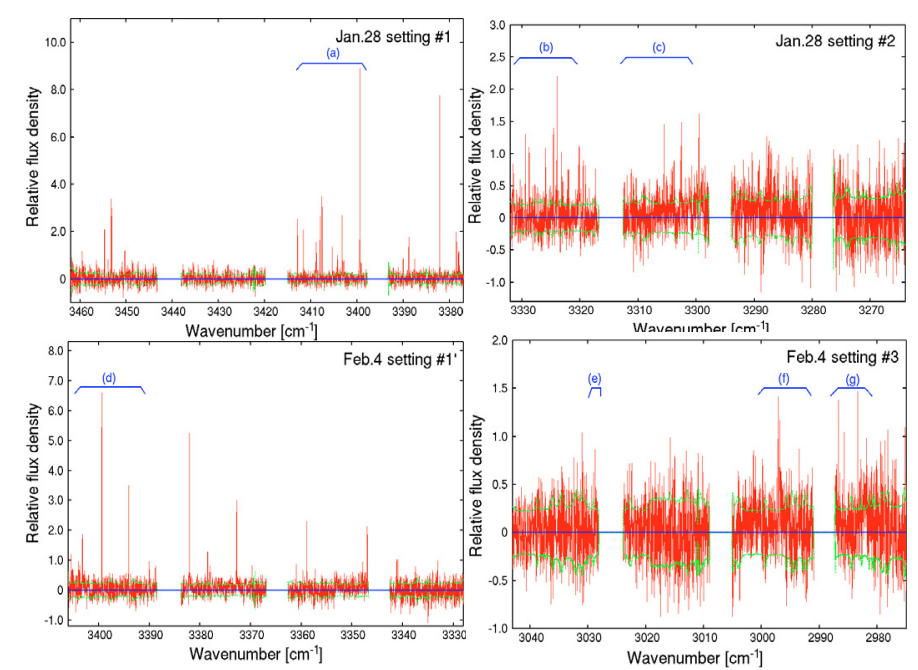

Fig. 2. Spectra of comet $8 \mathrm{P} /$ Tuttle. Each panel corresponds to each grating setting on each date. Part of spectra indicated by a)-g) are also shown in Fig. 3 for more detail. Solid lines and dashed lines are zero levels and $\pm 1 \sigma$ error levels, respectively in all panels. The field of view of the aperture is $0.2^{\prime \prime} \times \sim 0.8^{\prime \prime}$.

two 2-D Gaussian functions (one for the core and another for the wing part). The throughput of the slit was estimated based on this modeled profile. After that, we calibrated the cometary spectra based on the efficiencies determined for the standard star. Therefore, the telluric absorption was not corrected for the comet at this stage and this would be corrected for each emission line later. The difference in airmass between the comet and the standard star was taken into account by using the LBLRTM code.

The cometary continuum component (reflected sunlight) was modeled as a product of the smoothed continuum and the synthesized atmospheric transmittance calculated by the LBLRTM code. The continuum component was removed by using this modeled spectrum. The calibrated (but not corrected for the telluric absorption) cometary emission spectra are shown in Figs. 2 and 3, and the detected emission lines are listed in Table 2. Additional details of our observing procedure and data analysis can be obtained from Kobayashi et al. (2007) and Kawakita \& Kobayashi (2009). 
Table 1. Overview of the CRIRES observations.

\begin{tabular}{|c|c|c|c|c|c|c|c|c|c|}
\hline Date & $\begin{array}{l}\text { Time }^{a} \\
\text { (UT) }\end{array}$ & Settings & Molecules & $\begin{array}{c}\text { Wavelength } \\
\text { coverage }\left[\mathrm{cm}^{-1}\right]\end{array}$ & $\begin{array}{c}r^{b} \\
{[\mathrm{AU}]}\end{array}$ & $\begin{array}{c}\Delta^{c} \\
{[\mathrm{AU}]}\end{array}$ & $\begin{array}{c}\dot{\Delta}^{d} \\
{\left[\mathrm{~km} \mathrm{~s}^{-1}\right]}\end{array}$ & Airmass & $\begin{array}{c}\text { Slit PA } \\
{[\mathrm{deg}]}\end{array}$ \\
\hline \multirow{2}{*}{ January 28,2008} & $1: 28-2: 47$ & $\# 2$ & $\mathrm{H}_{2} \mathrm{O}, \mathrm{HCN}, \mathrm{C}_{2} \mathrm{H}_{2}$ & $3332.4-3263.4$ & 1.027 & 0.523 & 24.798 & 1.36 & 74 \\
\hline & $3: 13-4: 07$ & $\# 1$ & $\mathrm{H}_{2} \mathrm{O}$ & $3462.5-3377.0$ & 1.027 & 0.524 & 24.865 & 2.03 & 74 \\
\hline \multirow[t]{3}{*}{ February 4, 2008} & $0: 49-1: 54$ & $\# 1$ ' & $\mathrm{H}_{2} \mathrm{O}$ & $3406.2-3327.7$ & 1.035 & 0.621 & 24.187 & 1.27 & 80 \\
\hline & $2: 20-3: 23$ & $\# 3$ & $\mathrm{CH}_{4}, \mathrm{CH}_{3} \mathrm{OH}, \mathrm{C}_{2} \mathrm{H}_{6}$ & $3404.8-2974.2$ & 1.035 & 0.622 & 24.252 & 1.69 & 80 \\
\hline & $3: 53-4: 11$ & \#4 & $\mathrm{CH}_{3} \mathrm{OH}$ & $2865.3-2799.6$ & 1.035 & 0.622 & 24.275 & 2.52 & 80 \\
\hline
\end{tabular}

${ }^{a} r, \Delta$, and $\dot{\Delta}$ listed in Cols. $6-8$ are the values at the midpoint of this time interval; ${ }^{b}$ Heliocentric distance; ${ }^{c}$ Geocentric distance; ${ }^{d}$ Topocentric velocity of the comet.
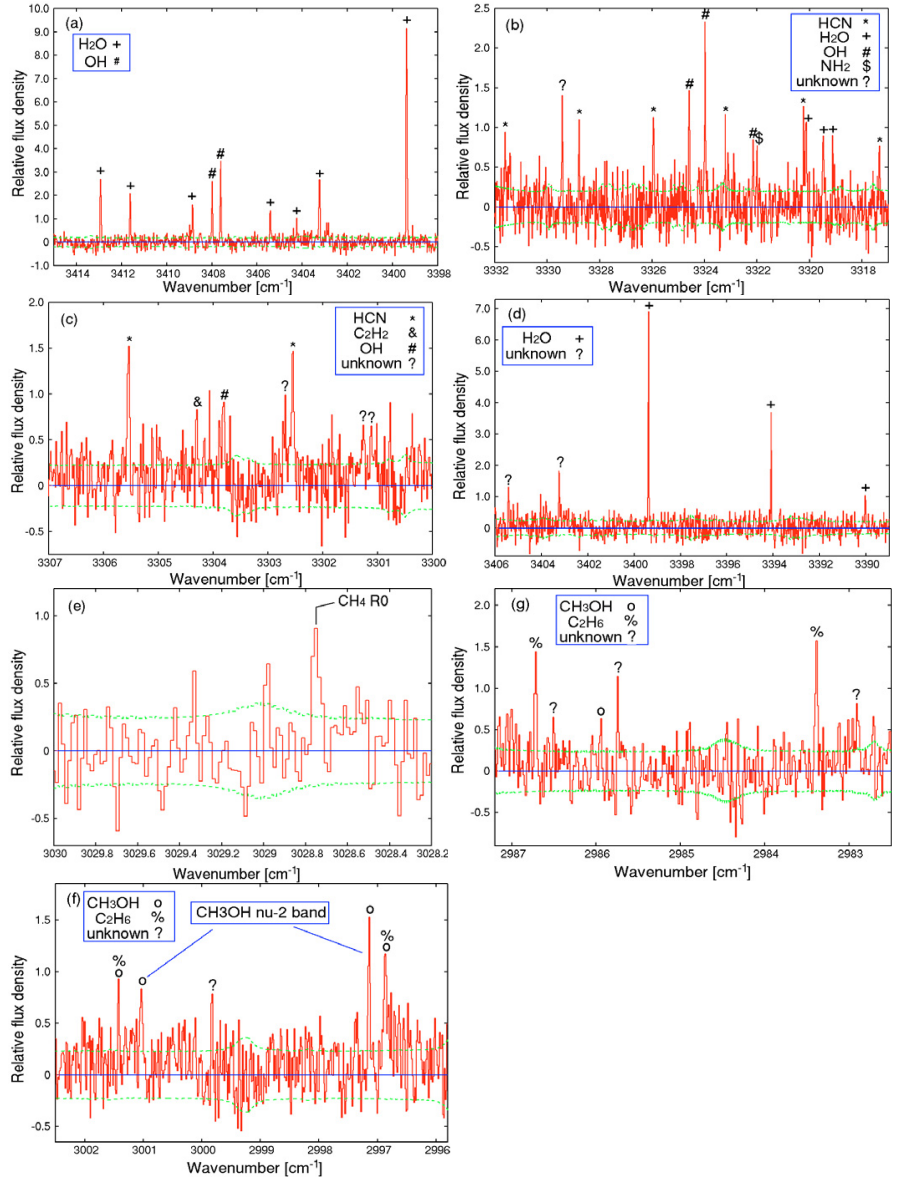

Fig. 3. Selected spectra of comet $8 \mathrm{P} /$ Tuttle. a) Spectrum of $\mathrm{H}_{2} \mathrm{O}$ and OH observed on January 28, 2008 (setting \#1, see Table 1). b) and c) Spectra of $\mathrm{HCN}$ and $\mathrm{C}_{2} \mathrm{H}_{2}$ observed on January 28, 2008 (setting \#2). d) Spectrum of $\mathrm{H}_{2} \mathrm{O}$ observed on February 4, 2008 (setting \#1'). e)g) Spectrum with $\mathrm{CH}_{4} v_{3} \mathrm{R} 0$ line, the $v_{2}$ band of $\mathrm{CH}_{3} \mathrm{OH}$ and the $v_{7}$ band of $\mathrm{C}_{2} \mathrm{H}_{6}$ observed on February 4, 2008 (setting \#3). Solid lines and dashed lines are zero levels and $\pm 1 \sigma$ error levels, respectively in all panels. The field of view of the aperture is $0.2^{\prime \prime} \times \sim 0.8^{\prime \prime}$.

\section{Results}

The gas production rates $\left(Q, \mathrm{~s}^{-1}\right)$ were calculated from the observed spectra using modeled fluorescence efficiencies ( $g$-factors) for the appropriate rotational excitation temperature $\left(T_{\text {rot }}\right)$. Except for $\mathrm{CH}_{3} \mathrm{OH}$ and $\mathrm{C}_{2} \mathrm{H}_{6}$, we used the $g$-factors derived from the fluorescence excitation models described in Kobayashi \& Kawakita (2009).

Ro-vibrational lines from fundamental vibrational bands were observed for $\mathrm{HCN}, \mathrm{C}_{2} \mathrm{H}_{2}, \mathrm{CH}_{4}, \mathrm{C}_{2} \mathrm{H}_{6}$ and $\mathrm{CH}_{3} \mathrm{OH}$. These molecules are pumped from the ground vibrational state to the upper vibrational state by the solar radiation field and then relax down to the ground vibrational state. The population distribution among the rotational levels in the ground vibrational state is described by the Boltzmann distribution at a given rotational temperature $T_{\text {rot }}$.

Lines from the fundamental bands of $\mathrm{H}_{2} \mathrm{O}$ cannot be detected by ground-based observations because of extinction from associated telluric lines. Instead, "hot-bands" are routinely observed from ground-based observatories (Dello Russo et al. 2004, 2005). The fluorescence excitation model of water hot-bands is based on Dello Russo et al. (2004, 2005); $\mathrm{H}_{2} \mathrm{O}$ molecules are pumped from the ground vibrational state to the upper vibrational states by the solar radiation field and then cascade to the ground vibrational state through the intermediate vibrational states. The population distribution in the ground vibrational state is described by the Boltzmann distribution as for $\mathrm{HCN}, \mathrm{C}_{2} \mathrm{H}_{2}$, $\mathrm{CH}_{4}, \mathrm{C}_{2} \mathrm{H}_{6}$, and $\mathrm{CH}_{3} \mathrm{OH}$.

The detection of several lines of $\mathrm{H}_{2} \mathrm{O}$ and $\mathrm{HCN}$ allows us to determine the rotational temperature $T_{\text {rot }}$ of $\mathrm{H}_{2} \mathrm{O}$ on Jan. 28 and Feb. 4 and of HCN on Jan. 28. We used the method outlined by Dello Russo et al. (2004). We plotted the ratios of line flux to the corresponding line $g$-factor $(F / g)$ vs. the upper state rotational energy ( $E^{\prime}-E^{\prime}$ (lowest)) (Fig. 4). At the appropriate $T_{\text {rot }}$, the slope of the line for $F / g$ vs. ( $E^{\prime}-E^{\prime}$ (lowest)) should be equal to zero because at this temperature $F / g$ should be independent of $\left(E^{\prime}-E^{\prime}\right.$ (lowest)).

We determined the best $T_{\text {rot }}$ for $\mathrm{H}_{2} \mathrm{O}$ by the $\chi^{2}$-fitting method. Errors $( \pm 1 \sigma)$ in $T_{\text {rot }}$ and the ortho-to-para ratio (OPR) are estimated based on the reduced $\chi^{2}$. The $T_{\text {rot }}$ of $\mathrm{H}_{2} \mathrm{O}$ is determined to be $70 \pm 15 \mathrm{~K}$ and $65_{-13}^{+15} \mathrm{~K}$ for Jan. 28 and Feb. 4 , respectively. The OPR for $\mathrm{H}_{2} \mathrm{O}$ was also determined but it was poorly constrained. The best-fit values are $2.35_{-0.58}^{+0.77}$ and $2.56_{-0.74}^{+1.50}$ on Jan. 28 and Feb. 4, respectively. These values are consistent with the high-temperature limit $(\mathrm{OPR}=3)$ within their uncertainties. Therefore, we assume OPR $=3$ in the following part. For HCN, we determined $T_{\text {rot }}=54 \pm 9 \mathrm{~K}$ on Jan. 28 (Fig. 4). The $\pm 1 \sigma$ uncertainty for the $T_{\text {rot }}$ is estimated from the error in the slope. The rotational temperatures for $\mathrm{H}_{2} \mathrm{O}$ and $\mathrm{HCN}$ on Jan. 28 are consistent within their uncertainties. The spatial profiles of $\mathrm{H}_{2} \mathrm{O}$ and $\mathrm{HCN}$ are also shown in Fig. 4 and these profiles are consistent with each other. These facts suggest that the rotational excitation of these molecules was controlled by intermolecular collisions in the inner coma, so these molecules were thermalized. Therefore, we assumed a $T_{\text {rot }}$ of $70 \mathrm{~K}$ on both Jan. 28 and Feb. 4 for molecules where rotational temperatures could not be directly determined $\left(\mathrm{C}_{2} \mathrm{H}_{2}, \mathrm{CH}_{4}, \mathrm{C}_{2} \mathrm{H}_{6}\right.$ and $\left.\mathrm{CH}_{3} \mathrm{OH}\right)$.

For $\mathrm{C}_{2} \mathrm{H}_{6}, g$-factors of detected lines were provided by Dello Russo et al. (2001) at $T_{\text {rot }}=70 \mathrm{~K}$. We used those $g$-factors to determine the mixing ratio of $\mathrm{C}_{2} \mathrm{H}_{6}$. Usually, $\mathrm{CH}_{3} \mathrm{OH}$ production rates from high-resolution infrared measurements are determined from the flux of the $v_{3} Q$-branch. However, the $v_{3}$ 

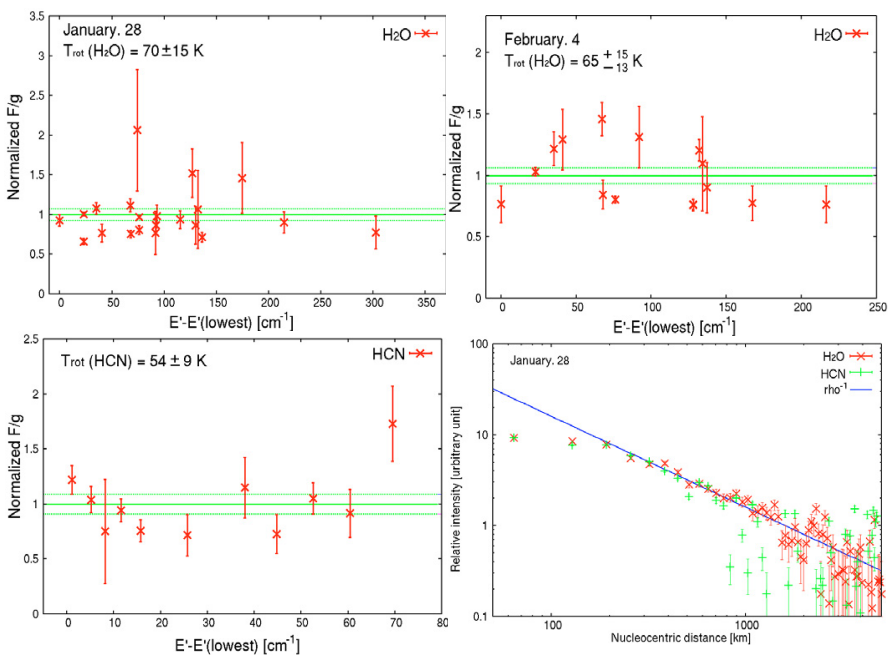

Fig. 4. Rotational temperature analysis of $\mathrm{H}_{2} \mathrm{O}$ (on January 28 and February 4, 2008) and HCN (on January 28, 2008), and spatial profiles of $\mathrm{H}_{2} \mathrm{O}$ and $\mathrm{HCN}$ (lower-right panel). For the rotatinal temperature analysis, we plot $F / g$ vs. $E^{\prime}-E^{\prime}$ (lowest) (upper state energy), where $F$ is the line flux and $g$ is the line $g$-factor. If the rotational temperature ( $T_{\text {rot }}$ ) used to compute the $g$-factors is correct, the line fitted to the $F / g$ values should be flat. The inferred $T_{\text {rot }}$ of $\mathrm{H}_{2} \mathrm{O}$ is $70 \pm 15 \mathrm{~K}$ and $65_{-13}^{+15} \mathrm{~K}$ on January 28 and February 4 , respectively. $T_{\text {rot }}$ of $\mathrm{HCN}$ is determined as $54 \pm 9 \mathrm{~K}$. The solid lines in the plots are the averaged $F / g$ values (because $F / g$ is normalized by the averaged $F / g$, the averaged $F / g$ is unity). The errors-bars of $T_{\text {rot }}$ and dashed lines in the figures correspond to $\pm 1 \sigma$ errors. For spatial profiles, the solid blue line corresnoinds to $\rho^{-1}$ profile ( $\rho$ : nucleocentric distance), and the error-bars correspond to $\pm 1 \sigma$ errors for each data point.

$Q$-branch was observed when the comet was at high airmass $(\sim 2.5)$, so flux-calibration for this setting was more uncertain. Therefore, a $\mathrm{CH}_{3} \mathrm{OH}$ production rate was determined from the flux of $v_{2}$ lines detected near $3000 \mathrm{~cm}^{-1}$. These same lines were detected in comet $\mathrm{C} / 1999 \mathrm{H} 1$ (Lee) along with the $v_{3} Q$-branch of $\mathrm{CH}_{3} \mathrm{OH}$, and fluxes for these lines were reported in Dello Russo et al. (2006). The gas rotational temperatures derived from C/1999 H1 (Lee) were between 70 and $80 \mathrm{~K}$ (Mumma et al. 2001a; Dello Russo et al. 2005), similar to the derived gas rotational temperatures reported here for $8 \mathrm{P} /$ Tuttle. Therefore, assuming the relative intensities of the $v_{2} \mathrm{CH}_{3} \mathrm{OH}$ lines and the $v_{3}$ $Q$-branch are the same in both comets, effective $g$-factors could be determined for the $v_{2} \mathrm{CH}_{3} \mathrm{OH}$ lines using the modeled $g$ factor for the $v_{3} Q$-branch. We used the $\mathrm{CH}_{3} \mathrm{OH} v_{3} Q$-branch $g$-factor at $70 \mathrm{~K}$ used by Bonev et al. (2008) and Boehnhardt et al. (2008) to enable a direct comparison with their derived $\mathrm{CH}_{3} \mathrm{OH}$ production rate (DiSanti, private comm.).

Gas production rates are determined based on the isotropic expanding coma model (e.g., Kobayashi et al. 2007). We assumed the expansion velocity of gas to be $0.8 \times r^{-0.5} \mathrm{~km} \mathrm{~s}^{-1}$ ( $r$ is the heliocentric distance of the comet in AU). Photodissociation rates of the molecules are taken from Huebner et al. (1992). In order to determine the absolute production rates, the " $Q$ curve" method (correction for the slit-loss of the comet) was used (DiSanti \& Mumma 2008). We assumed that the "growth factor" (a ratio of the global $Q$ relative to the nucleuscentered $Q$ ) is the same for all species observed at the same time. For example, we determined the growth factor of $\mathrm{C}_{2} \mathrm{H}_{6}$ from its emission lines and we applied it to $\mathrm{CH}_{4}$ and $\mathrm{CH}_{3} \mathrm{OH}$ (these emission lines were observed simultaneously) since the emission lines of both $\mathrm{CH}_{4}$ and $\mathrm{CH}_{3} \mathrm{OH}$ are too weak to determine the growth-factor based on their signals only. We determined
Table 3. Production rates and mixing ratios of comet 8P/Tuttle.

January 28, 2008

\begin{tabular}{|c|c|c|c|}
\hline Molecules & $\begin{array}{l}T_{\text {rot }} \\
{[\mathrm{K}]}\end{array}$ & $\begin{array}{l}\text { Production rate } \\
{\left[\text { molecules s }^{-1} \text { ] }\right.}\end{array}$ & $\begin{array}{c}\text { Mixing ratio } \\
{[\%]}\end{array}$ \\
\hline $\mathrm{H}_{2} \mathrm{O}$ & $70 \pm 15$ & $(4.6 \pm 0.4) \times 10^{28}$ & 100 \\
\hline $\mathrm{HCN}$ & $54 \pm 9$ & $(3.4 \pm 1.1) \times 10^{25}$ & $0.07 \pm 0.02$ \\
\hline $\mathrm{C}_{2} \mathrm{H}_{2}$ & $(70)^{*}$ & $(2.1 \pm 0.7) \times 10^{25}$ & $0.05 \pm 0.02$ \\
\hline \multicolumn{4}{|c|}{ February 4, 2008} \\
\hline "Molecules & $\begin{array}{l}T_{\text {rot }} \\
{[\mathrm{K}]}\end{array}$ & $\begin{array}{l}\text { Production rate } \\
{\left[\text { molecules s }^{-1} \text { ] }\right.}\end{array}$ & $\begin{array}{c}\text { Mixing ratio } \\
{[\%]}\end{array}$ \\
\hline $\mathrm{H}_{2} \mathrm{O}$ & $65_{-13}^{+15}$ & $(3.0 \pm 0.2) \times 10^{28}$ & 100 \\
\hline $\mathrm{CH}_{4}$ & $(70)^{-13}$ & $(1.7 \pm 1.1) \times 10^{26}$ & $0.6 \pm 0.4$ \\
\hline $\mathrm{C}_{2} \mathrm{H}_{6}$ & $(70)^{*}$ & $(6.7 \pm 1.3) \times 10^{25}$ & $0.23 \pm 0.04$ \\
\hline $\mathrm{CH}_{3} \mathrm{OH}$ & $(70)^{*}$ & $(9.7 \pm 1.3) \times 10^{26}$ & $3.3 \pm 0.4$ \\
\hline
\end{tabular}

* This value is adopted, and is based on $\mathrm{H}_{2} \mathrm{O}$ measurements (see text).

the growth-factors of $\mathrm{H}_{2} \mathrm{O}$ (January 28: 2.22; February 4: 2.55) and $\mathrm{C}_{2} \mathrm{H}_{6}$ (3.54) and we applied them to other molecules in each setting. On February 4, the growth-factor of $\mathrm{C}_{2} \mathrm{H}_{6}$ is $40 \%$ higher than that of $\mathrm{H}_{2} \mathrm{O}$. This difference might be caused by the difference of seeing for these settings (seeing is much better on setting \#1' than setting \#3).

The mixing ratios of parent volatiles in $8 \mathrm{P} /$ Tuttle are determined as production rate ratios relative to $\mathrm{H}_{2} \mathrm{O}$ (i.e., $\left.Q(\mathrm{X}) / Q\left(\mathrm{H}_{2} \mathrm{O}\right)\right)$. For $\mathrm{HCN}$ and $\mathrm{C}_{2} \mathrm{H}_{2}$, we derived the mixing ratios by comparing directly their emission lines with $\mathrm{H}_{2} \mathrm{O}$ lines (taken simultaneously, see Table 2). The growth factors are canceled in these cases. In other cases $\left(\mathrm{CH}_{4}, \mathrm{C}_{2} \mathrm{H}_{6}\right.$, and $\left.\mathrm{CH}_{3} \mathrm{OH}\right)$, the molecular emission lines were not observed with $\mathrm{H}_{2} \mathrm{O}$ simultaneously and both the growth factors of $\mathrm{H}_{2} \mathrm{O}$ and each molecular species are used to derive the mixing ratios. The uncertainties in production rates and mixing ratios are dominated by systematic uncertainty (e.g., accuracy of the fluorescence model for each molecule, accuracy of model calculation of the atmospheric transmittance etc.) and not generally by the stochastic noise mainly caused by sky-background emission. We employed the standard deviation of the $F / g$ values as the systematic uncertainty. Production rates and mixing ratios for all detected molecules are listed in Table 3.

\section{Discussion}

Radar observations obtained by Harmon et al. (2008) suggest that the nucleus of $8 \mathrm{P} /$ Tuttle is a "contact binary" with a rotational period of $11.4 \mathrm{~h}$. Because of this, Bonev et al. (2008) hypothesized that the components of $8 \mathrm{P} /$ Tuttle might be chemically heterogeneous. Comparing mixing ratios obtained from our observations to those obtained from other high-resolution infrared observations carried out in December 2007 and January 2008 (Bonev et al. 2008; Boehnhardt et al. 2008) suggests no evidence for temporal variation of the coma composition in $8 \mathrm{P} /$ Tuttle (Table 4 and Fig. 5) because these mixing ratios are consistent within three $\sigma$ error-bars. This is confirmed by a $\chi^{2}$ test of hypothsis which, even at the 0.01 significance level, does not allow us to reject the hypothesis of constant mixing ratios. We note that the emission lines used to determine the mixing ratio of $\mathrm{CH}_{3} \mathrm{OH}$ in our analysis and in others (Bonev et al. 2008; Boehnhardt et al. 2008) were different i.e., the $v_{2}$ lines in ours as listed in Table 2 and the $v_{3} Q$-branch in others. This implies that the error of $g$ factor we used may be larger because we converted the $g$-factor of the $v_{3} Q$-branch to $v_{2}$ lines based on the observations of comet 
Table 4. Mixing ratios in comet 8P/Tuttle.

\begin{tabular}{cccc}
\hline \hline Molecules & This work & Bonev et al. (2008) & Boehnhardt et al. (2008) \\
\hline $\mathrm{HCN}$ & $0.07 \pm 0.02$ & $0.07 \pm 0.02$ & \\
$\mathrm{C}_{2} \mathrm{H}_{2}$ & $0.05 \pm 0.02$ & $<0.04$ & \\
$\mathrm{CH}_{4}$ & $0.6 \pm 0.4$ & $0.37 \pm 0.07$ & $0.36 \pm 0.09 / 0.37 \pm 0.08^{1}$ \\
$\mathrm{C}_{2} \mathrm{H}_{6}$ & $0.23 \pm 0.04$ & $0.24 \pm 0.03$ & $0.30 \pm 0.09 / 0.28 \pm 0.06^{1}$ \\
$\mathrm{CH}_{3} \mathrm{OH}$ & $3.3 \pm 0.4$ & $2.18 \pm 0.07$ & $3.36 \pm 0.40 / 3.24 \pm 0.32^{2}$ \\
\hline
\end{tabular}

${ }^{1}$ Measurements of January 26/27.

${ }^{2}$ Measurements of January 27/28.

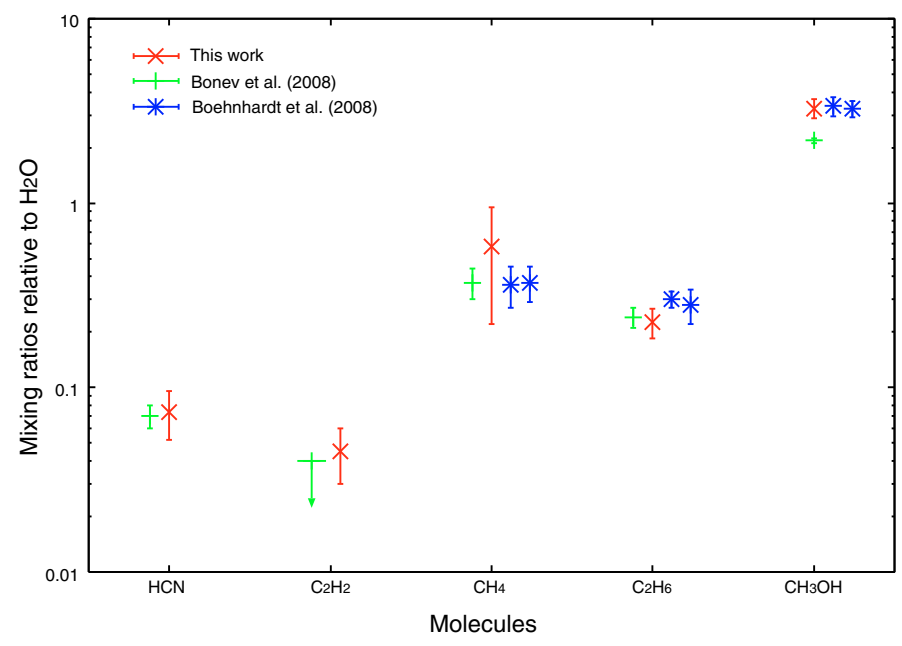

Fig. 5. Comparison of mixing ratios in comet $8 \mathrm{P} /$ Tuttle measured at different dates (this work, Bonev et al. 2008; and Boehnhardt et al. 2008, see Table 4). All error-bars are $\pm 1 \sigma$ error levels.

Lee for $\mathrm{CH}_{3} \mathrm{OH}$. Since we did not consider the error of the $g$ factor of the $v_{3} Q$-branch and the error for the conversion from the $v_{3} Q$-branch to the $v_{2}$ lines, the error of $\mathrm{CH}_{3} \mathrm{OH}$ mixing ratio might be larger.

The absolute production rate of water in late January is almost the same between our work on January 28 UT and Boehnhardt et al. (2008) on January 27 UT. Given the rotation period measured by Harmon et al. (2008) and Lamy et al. (2008), our observations of January 28 and February 4 were separated by $\approx 14.65$ rotations, i.e., they were done at rotation phases separated by one third of the nucleus rotation period. The measurements of Boehnhardt et al. (2008) are at phases in between our measurements. Given the uncertainties in the rotation period of $8 \mathrm{P} /$ Tuttle, the rotation phase of the December observations (Bonev et al. 2008) cannot be properly scaled with respect to our measurements. If the nucleus had two components of significantly different chemical composition, as suggested by Bonev et al. (2008), variations of the coma composition should have been observed. Based on these near-IR measurements, there is no evidence for chemical heterogeneity within the nucleus of 8P/Tuttle.

We also compared the mixing ratios with other HFCs and LPCs listed in DiSanti \& Mumma (2008), and summarized them in Table 5 and Fig. 6. Although the black bars shown in Fig. 6 indicate a wide range (by a factor of $\sim 10$ ) of mixing ratios, most of this variation is caused by C/1999 S4 (LINEAR) and C/2001 A2 (LINEAR). The former is highly depleted in organic volatiles while the latter is rich in organics (see Table 5). From near-IR measurements of comets, some chemical groups are proposed by Mumma et al. (2009); organics-enriched,-normal, and -depleted group. Comet C/1999 S4 (LINEAR) and C/2001 A2 (LINEAR)

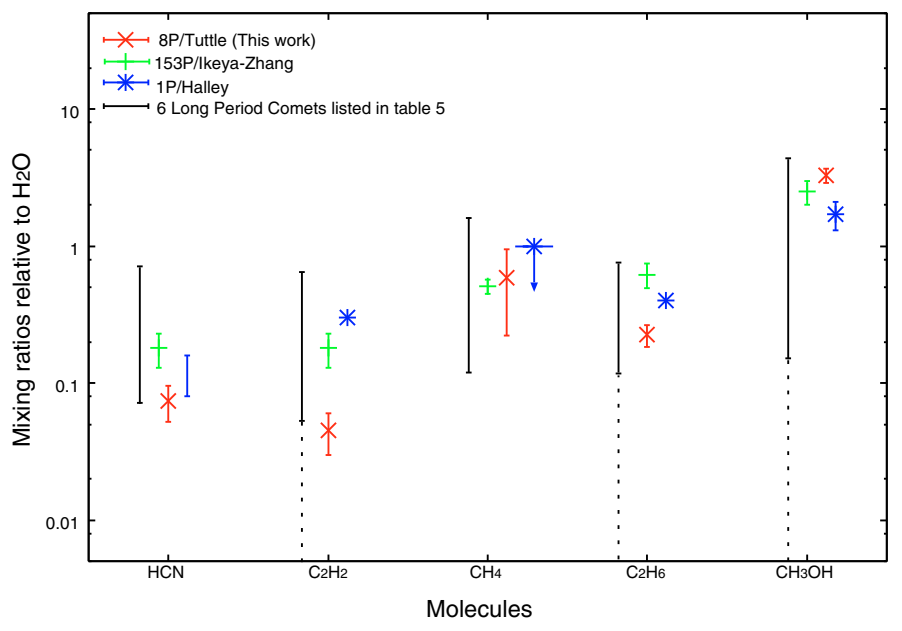

Fig. 6. Comparison between mixing ratios measured in $8 \mathrm{P} /$ Tuttle (this work) and in other Halley Family comets and 6 Long Period comets (DiSanti \& Mumma 2008, see Table 5). The black solid lines are the range of 6 Long Period comets. For the $\mathrm{C}_{2} \mathrm{H}_{2}, \mathrm{C}_{2} \mathrm{H}_{6}$, and $\mathrm{CH}_{3} \mathrm{OH}$ of C/1999 S4 (LINEAR) is derived the upper limit (these molecules are shown as the ranges with the dashed lines below solid lines). Although all mixing ratios are within the range for $6 \mathrm{LPCs}, \mathrm{HCN}$ and $\mathrm{C}_{2} \mathrm{H}_{2}$ are at the lower end of each range. In contrast, $\mathrm{CH}_{3} \mathrm{OH}$ is at the higher end of the range. All error bars are $\pm 1 \sigma$ error levels. Note that there are no reported error bars for some molecular species in the case of comet $1 \mathrm{P} /$ Halley $\left(\mathrm{HCN}, \mathrm{C}_{2} \mathrm{H}_{2}\right.$, and $\left.\mathrm{C}_{2} \mathrm{H}_{6}\right)$. For the $\mathrm{HCN}$ in comet $1 \mathrm{P} / \mathrm{Halley}$ we show the range reported in some reports (see the references in Table 5).

represent comets of the organics-depleted and the organicsenriched group, respectively. On the other hand, Crovisier et al. (2009) reported that there is no clear evidence of such grouping by chemistry in radio observations. The chemical taxonomy of comets is still under debate and the lack of samples makes this problem more complex. Therefore, we plotted the mixing ratios of comets without such a grouping, just as a range. In comparison to other HFCs (1P/Halley and 153P/Ikeya-Zhang), 8P/Tuttle is strongly depleted in $\mathrm{C}_{2} \mathrm{H}_{2}$ and may also be depleted in $\mathrm{HCN}$ and $\mathrm{C}_{2} \mathrm{H}_{6}$. On the other hand, in comparison to $6 \mathrm{LPCs}$, the mixing ratios in comet $8 \mathrm{P} /$ Tuttle are within the ranges typically seen, with $\mathrm{HCN}$ and $\mathrm{C}_{2} \mathrm{H}_{2}$ at the depleted end while $\mathrm{CH}_{3} \mathrm{OH}$ is in the upper range.

A similar composition was also reported by Bonev et al. (2008). They suggested that the composition of 8P/Tuttle was unusual and that it might be caused by chemical heterogeneity in the nucleus if the binary components are chemically distinct. However, as we mentioned above, the mixing ratios of species in $8 \mathrm{P} /$ Tuttle are not atypical and there is no evidence of heterogeneity in chemistry by comparing the composition on different dates. Does the chemistry of 8P/Tuttle suggest a different formation region than the HFCs and LPCs? HFCs and LPCs are thought to have formed in the region from 5-30 AU in the early solar nebula. JFCs likely formed in a more compact region (16-30 AU) (Morbidelli et al. 2008). While 8P/Tuttle may have formed in a different region of the early solar nebula from other HFCs and LPCs, based on the derived volatile mixing ratios there is no conclusive evidence.

Bonev et al. (2008) reported that $\mathrm{C}_{2} \mathrm{H}_{6}$ might be formed from $\mathrm{C}_{2} \mathrm{H}_{2}$ by hydrogen atom addition reactions, and that this conversion may have occurred with higher efficiency in $8 \mathrm{P} /$ Tuttle than in typical OC comets. Our observations show no conclusive evidence for this hypothesis. From our detection of $\mathrm{C}_{2} \mathrm{H}_{2}$ we determined that the mixing ratio of $\mathrm{C}_{2} \mathrm{H}_{2}$ to $\mathrm{H}_{2} \mathrm{O}$ is consistent 
Table 5. Mixing ratios of comet $8 \mathrm{P} /$ Tuttle, other HFCs and LPCs.

\begin{tabular}{ccccccc}
\hline \hline Comets & $\mathrm{HCN}$ & $\mathrm{C}_{2} \mathrm{H}_{2}$ & $\mathrm{CH}_{4}$ & $\mathrm{C}_{2} \mathrm{H}_{6}$ & $\mathrm{CH}_{3} \mathrm{OH}$ & Remarks \\
\hline 8P/Tuttle & $0.07 \pm 0.02$ & $0.05 \pm 0.02$ & $0.6 \pm 0.4$ & $0.23 \pm 0.04$ & $3.3 \pm 0.4$ & HFC, This work \\
153P/Ikeya-Zhang & $0.18 \pm 0.05^{1}$ & $0.18 \pm 0.05^{1}$ & $0.51 \pm 0.06^{2}$ & $0.62 \pm 0.18^{3}$ & $2.5 \pm 0.5^{4}$ & HFC \\
1P/Halley & $0.08-0.16^{5,6,7}$ & $\sim 0.3^{8}$ & $<1^{8}$ & $\sim 0.4^{8}$ & $1.7 \pm 0.4^{9}$ & HFC \\
C/1996 B2 & $0.18 \pm 0.04^{10}$ & $0.16 \pm 0.08^{11}$ & $0.79 \pm 0.08^{2,12}$ & $0.62 \pm 0.07^{9,13}$ & $1.7 \pm 0.4^{14}$ & LPC \\
C/1995 O1 & $0.27 \pm 0.04^{11}$ & $0.31 \pm 0.1^{11}$ & $1.45 \pm 0.16^{2,15}$ & $0.56 \pm 0.049^{16}$ & $2.4 \pm 0.3^{17}$ & LPC \\
C/1999 H1 & $0.29 \pm 0.02^{18}$ & $0.27 \pm 0.03^{18}$ & $1.45 \pm 0.18^{2}$ & $0.67 \pm 0.07^{18}$ & $2.1 \pm 0.5^{18}$ & LPC \\
C/2001 A2 & $0.6 \pm 0.01^{19}$ & $0.5 \pm 0.1^{19}$ & $1.2 \pm 0.2^{20}$ & $0.5 \pm 0.1^{19}$ & $3.9 \pm 0.4^{19}$ & LPC \\
C/1999 S4 & $0.10 \pm 0.03^{21}$ & $<0.12^{21}$ & $0.18 \pm 0.06^{2,21}$ & $<0.12^{21}$ & $<0.15^{21}$ & LPC \\
C/2004 Q2 & $0.16 \pm 0.01^{22}$ & $0.054 \pm 0.004^{22}$ & $1.0 \pm 0.1^{22}$ & $0.42 \pm 0.01^{22}$ & $2.7 \pm 0.1^{22}$ & LPC \\
\hline
\end{tabular}

HFC : Halley Family Comet, LPC : Long Period Comet.

${ }^{1}$ Magee-Sauer et al. (2002a), ${ }^{2}$ Gibb et al. (2003), ${ }^{3}$ Dello Russo et al. (2002a), ${ }^{4}$ DiSanti et al. (2002), ${ }^{5}$ Bockelée-Morvan et al. (1987), ${ }^{6}$ Schloerb et al. (1986), ${ }^{7}$ Despois et al. (1986), ${ }^{8}$ Eberhardt (1999), ${ }^{9}$ Eberhardt et al. (1994), ${ }^{10}$ Magee-Sauer et al. (2002b), ${ }^{11}$ Magee-Sauer et al. (2001), ${ }^{12}$ Mumma et al. (1996), ${ }^{13}$ Dello Russo et al. (2002b), ${ }^{14}$ Biver et al. (1999a), ${ }^{15}$ Weaver et al. (1997), ${ }^{16}$ Dello Russo et al. (2001), ${ }^{17}$ Biver et al. (1999b), ${ }^{18}$ Mumma et al. (2001a), ${ }^{19}$ Magee-Sauer et al. (2008), ${ }^{20}$ Gibb et al. (2007), ${ }^{21}$ Mumma et al. (2001b), ${ }^{22}$ Kobayashi \& Kawakita (2009) (For $\mathrm{CH}_{3} \mathrm{OH}$, the same $g$-factor is used as Bonev's and Boehnhardt's. Mixing ratio listed here is higher by a factor of two than the reported value in their original paper see, Kobayashi \& Kawakita 2009.)

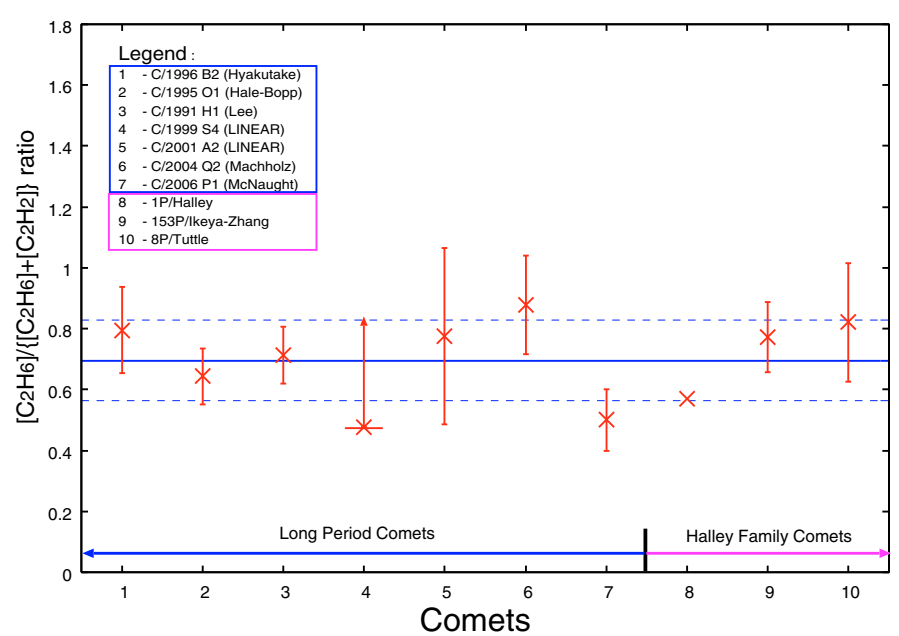

Fig. 7. The $\mathrm{C}_{2} \mathrm{H}_{6} /\left(\mathrm{C}_{2} \mathrm{H}_{2}+\mathrm{C}_{2} \mathrm{H}_{6}\right)$ ratio in comets listed in Table 6 . The $\mathrm{C}_{2} \mathrm{H}_{6} /\left(\mathrm{C}_{2} \mathrm{H}_{2}+\mathrm{C}_{2} \mathrm{H}_{6}\right)$ ratio is considered as the conversion rate from $\mathrm{C}_{2} \mathrm{H}_{2}$ to $\mathrm{C}_{2} \mathrm{H}_{6}$ by hydrogen-addition reactions on cold grains in the solar nebula (or in the molecular cloud). All comets show similar conversion rates. The solid line shows the mean value of the $\mathrm{C}_{2} \mathrm{H}_{6} /\left(\mathrm{C}_{2} \mathrm{H}_{2}+\mathrm{C}_{2} \mathrm{H}_{6}\right)$ ratio and dashed lines show the $\pm 1 \sigma$ error levels of the $\mathrm{C}_{2} \mathrm{H}_{6} /\left(\mathrm{C}_{2} \mathrm{H}_{2}+\mathrm{C}_{2} \mathrm{H}_{6}\right)$ ratio. All error-bars are $\pm 1 \sigma$ error levels.

with the upper-limit reported in Bonev et al. (2008). In order to test this hypothesis, we use the $\mathrm{C}_{2} \mathrm{H}_{6} /\left(\mathrm{C}_{2} \mathrm{H}_{6}+\mathrm{C}_{2} \mathrm{H}_{2}\right)$ ratio to estimate the conversion rate from $\mathrm{C}_{2} \mathrm{H}_{6}$ to $\mathrm{C}_{2} \mathrm{H}_{2}$. We compared the ratio obtained in $8 \mathrm{P} /$ Tuttle with other HFCs and LPCs listed in Table 5. Table 6 and Fig. 7 show the $\mathrm{C}_{2} \mathrm{H}_{6} /\left(\mathrm{C}_{2} \mathrm{H}_{6}+\mathrm{C}_{2} \mathrm{H}_{2}\right)$ ratios in these different comets. The conversion efficiency from $\mathrm{C}_{2} \mathrm{H}_{2}$ to $\mathrm{C}_{2} \mathrm{H}_{6}$ in $8 \mathrm{P} /$ Tuttle is consistent with the values obtained in other HFCs and LPCs within the limitations of sample size (within the 99\% confidence limit (hereafter, c.1.), see Fig. 7).

Bonev et al. (2008) also reported that the mixing ratios of $\mathrm{HCN}$ and $\mathrm{C}_{2} \mathrm{H}_{2}$ are inconsistent with these species being the only native precursors of the $\mathrm{CN}$ and $\mathrm{C}_{2}$ radicals observed at optical wavelengths. We computed $\log _{10}\left[Q(\mathrm{HCN}) / Q\left(\mathrm{H}_{2} \mathrm{O}\right)\right]$, $\log _{10}\left[Q\left(\mathrm{C}_{2} \mathrm{H}_{2}\right) / Q\left(\mathrm{H}_{2} \mathrm{O}\right)\right]$ and $\log _{10}\left[Q\left(\mathrm{C}_{2} \mathrm{H}_{2}\right) / Q(\mathrm{HCN})\right]$ and compared our results with optical results (see Table 7), including a measurement of the $\mathrm{C}_{2} / \mathrm{CN}$ ratio at a time coincident with our CRIRES observations (Jehin et al. 2009). Possible precursors of $\mathrm{C}_{2}$ observed in the near infrared are
$\mathrm{C}_{2} \mathrm{H}_{2}$ and $\mathrm{C}_{2} \mathrm{H}_{6}$. Although $\mathrm{C}_{2} \mathrm{H}_{6}$ is not a direct parent of $\mathrm{C}_{2}$, it may contribute to its abundance. According to Helbert et al. (2005), $\mathrm{C}_{2} \mathrm{H}_{6}$ can photodissociate to $\mathrm{C}_{2} \mathrm{H}_{5}(\sim 33 \%)$ and $\mathrm{C}_{2} \mathrm{H}_{4}(\sim 37 \%)$. All $\mathrm{C}_{2} \mathrm{H}_{5}$ and a fraction of $\mathrm{C}_{2} \mathrm{H}_{4}(\sim 44 \%)$ photodissociate to $\mathrm{C}_{2} \mathrm{H}_{2}$. Finally, all of $\mathrm{C}_{2} \mathrm{H}_{2}$ is photodissociated to $\mathrm{C}_{2}$. Based on this $\mathrm{C}_{2}$ is formed from $\mathrm{C}_{2} \mathrm{H}_{6}$ at about $50 \%$ yield $\left(\sim 33 \%\left(\mathrm{C}_{2} \mathrm{H}_{6} \rightarrow \mathrm{C}_{2} \mathrm{H}_{5} \rightarrow \mathrm{C}_{2} \mathrm{H}_{2}\right)+\sim 16 \%\right.$ $\left.\left(\mathrm{C}_{2} \mathrm{H}_{6} \rightarrow \mathrm{C}_{2} \mathrm{H}_{4} \rightarrow \mathrm{C}_{2} \mathrm{H}_{2}\right)\right)$. We note that this is only an approximation as these branching ratios are uncertain and dependent on the wavelength of the irradiating photon (Helbert et al. 2005). Assuming the branching ratios are correct, the mixing ratio $\log _{10}\left[Q\left(\mathrm{C}_{2}\right) / Q(\mathrm{OH})\right] \sim \log _{10}\left[\left(Q\left(\mathrm{C}_{2} \mathrm{H}_{2}\right)+0.5 Q\left(\mathrm{C}_{2} \mathrm{H}_{6}\right)\right) / Q\left(\mathrm{H}_{2} \mathrm{O}\right)\right]$ if $\mathrm{C}_{2} \mathrm{H}_{2}$ and $\mathrm{C}_{2} \mathrm{H}_{6}$ are the primary parents of $\mathrm{C}_{2}$. However, $\quad \log _{10}\left[Q\left(\mathrm{C}_{2}\right) / Q(\mathrm{OH})\right] \quad$ is significantly larger than $\log _{10}\left[\left(Q\left(\mathrm{C}_{2} \mathrm{H}_{2}\right)+0.5 Q\left(\mathrm{C}_{2} \mathrm{H}_{6}\right)\right) / Q\left(\mathrm{H}_{2} \mathrm{O}\right)\right]$, and this is true even assuming that $\mathrm{C}_{2} \mathrm{H}_{6}$ completely photodissociates to $\mathrm{C}_{2}$. Our derived mixing ratio for $\mathrm{HCN}$ is also too low to explain the $\mathrm{CN}$ abundance in $8 \mathrm{P} /$ Tuttle (e.g., $\left.\log _{10}[Q(\mathrm{CN}) / Q(\mathrm{OH})]>\log _{10}\left[Q(\mathrm{HCN}) / Q\left(\mathrm{H}_{2} \mathrm{O}\right)\right]\right)$. A direct comparison of the $\mathrm{HCN}$ and $\mathrm{CN}$ production rates measured simultaneously at the VLT on January 28 yields $\mathrm{CN} / \mathrm{HCN} \sim 3$ (Jehin et al. 2009). To explain the $\mathrm{CN}$ and $\mathrm{C}_{2}$ abundances in $8 \mathrm{P} /$ Tuttle, at least one additional precursor of both $\mathrm{CN}$ and $\mathrm{C}_{2}$ is needed. Our results agree with the conclusion of Bonev et al. (2008).

The discrepancy between gas production rates of parents and their daughter species was reviewed by Fray et al. (2003) for $\mathrm{HCN}$ and $\mathrm{CN}$. They compared $\mathrm{HCN}$ and $\mathrm{CN}$ production rates in eight comets and they found that the $\mathrm{CN}$ production rates are significantly higher than those of $\mathrm{HCN}$ in four comets while the $\mathrm{CN}$ and $\mathrm{HCN}$ production rates are similar to each other in other comets. An additional process is required for the $\mathrm{CN}$ production other than $\mathrm{HCN}$ photolysis in the former case.

\section{Summary and conclusion}

We observed comet 8P/Tuttle on January 28 and February 4 with the ESO VLT. Our observations were carried out in multiple spectral regions (optical and near IR), with this paper focusing on high dispersion spectroscopic observations of near IR data obtained with CRIRES. We determined the rotational temperatures for $\mathrm{H}_{2} \mathrm{O}$ and $\mathrm{HCN}$, and the production rates and abundance ratios of several parent volatiles in $8 \mathrm{P} /$ Tuttle. We compared our results to other high dispersion near IR spectroscopic 
Table 6. $\mathrm{C}_{2} \mathrm{H}_{6} /\left(\mathrm{C}_{2} \mathrm{H}_{6}+\mathrm{C}_{2} \mathrm{H}_{2}\right)$ ratios in comets.

\begin{tabular}{ccc}
\hline \hline Comets & $\mathrm{C}_{2} \mathrm{H}_{6} /\left(\mathrm{C}_{2} \mathrm{H}_{6}+\mathrm{C}_{2} \mathrm{H}_{2}\right)$ ratios & Remarks \\
\hline 8P/Tuttle & $0.8 \pm 0.2$ & This work \\
153P/Ikeya-Zhang & $0.8 \pm 0.4$ & DiSanti \& Mumma (2008) \\
1P/Halley & $\sim 0.6$ & DiSanti \& Mumma (2008) \\
$\mathrm{C} / 1996 \mathrm{~B} 2$ & $0.8 \pm 0.4$ & DiSanti \& Mumma (2008) \\
$\mathrm{C} / 1995 \mathrm{O} 1$ & $0.6 \pm 0.2$ & DiSanti \& Mumma (2008) \\
$\mathrm{C} / 1999 \mathrm{H} 1$ & $0.7 \pm 0.1$ & DiSanti \& Mumma (2008) \\
$\mathrm{C} / 2001 \mathrm{~A} 2$ & $0.8 \pm 0.1$ & DiSanti \& Mumma (2008) \\
$\mathrm{C} / 1999 \mathrm{~S} 4$ & $>0.5$ & DiSanti \& Mumma (2008) \\
$\mathrm{C} / 2004 \mathrm{Q} 2$ & $0.9 \pm 0.1$ & Kobayashi \& Kawakita (2009) \\
$\mathrm{C} / 2006 \mathrm{P} 1$ & $0.5 \pm 0.1$ & Dello Russo et al. (2009) \\
\hline
\end{tabular}

Table 7. $\mathrm{HCN} / \mathrm{H}_{2} \mathrm{O}(\mathrm{CN} / \mathrm{OH}), \mathrm{C}_{2} \mathrm{H}_{2} / \mathrm{H}_{2} \mathrm{O}\left(\mathrm{C}_{2} / \mathrm{OH}\right)$, and $\mathrm{C}_{2} \mathrm{H}_{2} / \mathrm{HCN}\left(\mathrm{C}_{2} / \mathrm{CN}\right)$ ratios in comet $8 \mathrm{P} /$ Tuttle.

\begin{tabular}{ccccc}
\hline \hline $\log _{10}\left[\frac{Q(\mathrm{CN})}{Q(\mathrm{OH})}\right]$ & $\log _{10}\left[\frac{Q\left(\mathrm{C}_{2}\right)}{Q \mathrm{OH})}\right]$ & $\log _{10}\left[\frac{Q\left(\mathrm{C}_{2}\right)}{Q(\mathrm{CN})}\right]$ & Remarks \\
\hline-2.54 & -2.39 & 0.15 & 1980 \\
-2.58 & -2.41 & 0.17 & 2007 \\
& & $0.11-0.15$ & 2008, Jehin et al. (2009) \\
\hline $\log _{10}\left[\frac{Q(\mathrm{HCN})}{Q\left(\mathrm{H}_{2} \mathrm{O}\right)}\right]$ & $\log _{10}\left[\frac{Q\left(\mathrm{C}_{2} \mathrm{H}_{2}\right)}{Q\left(\mathrm{H}_{2}\right)}\right]$ & $\log _{10}\left[\frac{Q\left(\mathrm{C}_{2} \mathrm{H}_{2}\right)}{Q(\mathrm{HCN})}\right]$ & $\log _{10}\left[\frac{Q\left(\mathrm{C}_{2} \mathrm{H}_{2}+\mathrm{C}_{2} \mathrm{H}_{6}(50 \%)\right)}{Q(\mathrm{HCN})}\right]$ & Remarks \\
\hline$-3.13_{-0.15}^{+0.11}$ & $-3.35_{-0.17}^{+0.13}$ & $-0.22_{-0.26}^{+0.17}$ & $0.33_{-0.18}^{+0.13}$ & This work \\
$-3.14_{-0.08}^{+0.04}$ & $<-3.41$ & $<-0.26$ & & Bonev et al. $(2008)$ \\
\hline
\end{tabular}

observations reported by Bonev et al. (2008) and Boehnhardt et al. (2008). Mixing ratios obtained from both studies are consistent with each other and we found no evidence of chemical heterogeneity from these observations. We also compared our results to those for other HFCs and LPCs. 8P/Tuttle is strongly depleted in $\mathrm{C}_{2} \mathrm{H}_{2}$ and may also be depleted in $\mathrm{HCN}$ and $\mathrm{C}_{2} \mathrm{H}_{6}$ relative to other HFCs. On the other hand, relative abundances of volatiles in $8 \mathrm{P} /$ Tuttle are not atypical when compared to LPCs, with $\mathrm{C}_{2} \mathrm{H}_{2}$ and $\mathrm{HCN}$ on the depleted end and $\mathrm{CH}_{3} \mathrm{OH}$ slightly enhanced. Although it is possible that the formation region of $8 \mathrm{P} /$ Tuttle is different from the formation regions of other LPCs and HFCs, we note that diverse chemistry is also seen within the Oort cloud population. We determined conversion efficiencies for hydrogen atom addition reactions through the $\mathrm{C}_{2} \mathrm{H}_{6} /\left(\mathrm{C}_{2} \mathrm{H}_{6}+\mathrm{C}_{2} \mathrm{H}_{2}\right)$ ratio in $8 \mathrm{P} /$ Tuttle and other comets. We found that $\mathrm{C}_{2} \mathrm{H}_{6} /\left(\mathrm{C}_{2} \mathrm{H}_{6}+\mathrm{C}_{2} \mathrm{H}_{2}\right)$ in $8 \mathrm{P} /$ Tuttle is consistent with other LPCs and HFCs (99\% c.l.) contrary to the high conversion efficiency reported by Bonev et al. (2008). However, we note that it is difficult to discern any trends as the number of comets where $\mathrm{C}_{2} \mathrm{H}_{6} /\left(\mathrm{C}_{2} \mathrm{H}_{6}+\mathrm{C}_{2} \mathrm{H}_{2}\right)$ ratios are measured is small. It is generally assumed that $\mathrm{CN}$ is formed directly from $\mathrm{HCN}$ and that $\mathrm{C}_{2}$ is formed directly from $\mathrm{C}_{2} \mathrm{H}_{2}$ and indirectly from $\mathrm{C}_{2} \mathrm{H}_{6}$ in cometary comae. However, Fray et al. (2003) reported a discrepancy between $\mathrm{CN}$ and $\mathrm{HCN}$ production rates in four comets (suggesting an additional process is required for the $\mathrm{CN}$ production). In the case of $8 \mathrm{P} /$ Tuttle the abundances of $\mathrm{HCN}, \mathrm{C}_{2} \mathrm{H}_{2}$ and $\mathrm{C}_{2} \mathrm{H}_{6}$ are insufficient to explain the $\mathrm{CN}$ and $\mathrm{C}_{2}$ abundances. So we concluded that at least one additional parent is needed for each species, as pointed out by Bonev et al. (2008).

Acknowledgements. The authors thank the anonymous referee for helpful comments. H. Kobayashi is JSPS fellow of the Ministry of Education, Science, Sports and Culture (Japan). EJ is Research Associate FNRS (Belgium), JM is Research Director FNRS and DH is Senior Research Associate FNRS.

\section{References}

A’Hearn, M. F., Mills, R. L., Schleicher, D. G., Osip, D. J., \& Birch, P. V. 1995, Icarus, 118, 223

Biver, N., Bockelée-Morvan, D., Crovisier, J., et al. 1999a, AJ, 118, 1850
Biver, N., Bockelée-Morvan, D., Colom, P., et al. 1999b, Earth Moon and Planets, 78, 5

Biver, N., Bockelée-Morvan, D., Crovisier, J., et al. 2002, Earth Moon and Planets, 90, 323

Bockelée-Morvan, D., Crovisier, J., Mumma, M. J., \& Weaver, H. A. 2004, in Comets II, ed. M. Festou, U. H. Keller, \& H. A. Weaver (Tucsom: the University of Arizona Press), 275

Bockelée-Morvan, D., Crovisier, J., Despois, D., et al. 1987, A\&A, 180, 253 Bonev, B. P., Mumma, M. J., Radeva, Y. L., et al. 2008, ApJ, 680, L61

Boehnhardt, H., Mumma, M. J., Villanueva, G. L., et al. 2008, ApJ, 683, L71 Clough, S. A., \& Iacono, M. J. 1995, J. Geophys. Res., 100, 16519

Crovisier, J., Biver, N., Bockelée-Morvan, D., Boissier, J., \& Colom, P. 2008, SF2A-2008: Proceedings of the Annual meeting of the French Society of Astronomy and Astrophysics, ed. C. Charbonnel, F. Combes, \& R. Samadi Available online at http://proc.sf2a. asso. fr, 40

Crovisier, J., Biver, N., Bockelée-Morvan, D., et al. 2009, Earth Moon and Planets, 105, 267

Dello Russo, N., Mumma, M. J., DiSanti, M. A., Magee-Sauer, K., \& Novak, R. 2001, Icarus, 153, 162

Dello Russo, N., DiSanti, M. A., Magee-Sauer, K., Gibb, E. L., \& Mumma, M. J. 2002a, Asteroids, Comets, Meteors., ESA SP-500, ESTEC (Noordwijk), 689 Dello Russo, N., Mumma, M. J., DiSanti, M. A., \& Magee-Sauer, K. 2002b, J. Geophys. Res., 107(E11), 5095

Dello Russo, N., DiSanti, M. A., Magee-Sauer, K., et al. 2004, Icarus, 168, 186 Dello Russo, N., Bonev, B. P., DiSanti, M. A., et al. 2005, ApJ, 621, 537

Dello Russo, N., Mumma, M. J., DiSanti, M. A., et al. 2006, Icarus, 184, 255

Dello Russo, N., Verback, R. J., Weaver, H. A., \& Lisse, C. M. 2009, Icarus, 200, 271

Despois, D., Crovisier, J., Bockelée-Morvan, D., et al. 1986, A\&A, 160, L11

DiSanti, M. A., Dello Russo, N., Magee-Sauer, K., et al. 2001, Asteroids, Comets, Meteors., ESA SP-500, ESTEC (Noordwijk), 571

DiSanti, M. A., \& Mumma, M. J. 2008, Space Sci. Rev., 138, 127

Duncan, M. J. 2008, Space Sci. Rev., 138, 109

Eberhardt, P., Meier, R., Krankowsky, D., \& Hodges, R. R. 1994, A\&A, 288, 315

Eberhardt, P. 1999, Space Sci. Rev., 90, 45

Fray, N., Bénilan, Y., Cottin, H., Gazeau, M.-C., \& Crovisier, J. 2003, Planet. Space Sci., 53, 1243

Gibb, E. L., Mumma, M. j., Dello Russo, N., DiSanti, M. A., \& Magee-Sauer, K. 2003, Icarus, 165, 319

Gibb, E. L., DiSanti, M. A., Magee-Sauer, K., et al. 2007, Icarus, 188, 224

Harmon, J. K., Nolan, M. C., Howell, E. S., Giorgini, J. D., \& Margi, C. 2008, Asteroids, Comets, Meteors., Abstract \#8025, Lunar and Planetary Institute Contribution No 1405, Houston (CD-ROM)

Helbert, J., Rauer, H., Boice, D. C., \& Huebner, W. F. 2005, A\&A, 442, 1107

Huebner, W. F., Keady, J. J., \& Lyon, S. P. 1992, A\&SS, 195, 1 
Jehin, E., Bockelée-Morvan, D., Dello Russo, N., et al. 2009, Earth Moon and Planets, 105, 343

Käufl, H.-U., \& 23 colleagues 2004, SPIE, 5482, 1218

Kawakita, H., \& Kobayashi, H. 2009, ApJ, 693, 388

Kobayashi, H., \& Kawakita, H. 2009, ApJ, 703, 121

Kobayashi, H., Kawakita, H., Mumma, M. J., et al. 2007, ApJ, 668, L75

Lamy, P. L., Toth, I., Jorda, L., et al. 2008, DPS meeting, BAAS, 40, 393

Levison, H. F. 1996, in Completing the Inventory of the Solar System, ed. T. Retting, \& J. M. Hahn, ASP Conf. Ser., 107, 173

Magee-Sauer, K., Mumma, M. J., DiSanti, M. A., Dello Russo, N., \& Retting, T. W. 1999, Icarus, 142, 498

Magee-Sauer, K., Mumma, M. J., DiSanti, M. A., \& Dello Russo, N. 2001, DPS meeting, BAAS, 33, 1076

Magee-Sauer, K., Dello Russo, N., DiSanti, M. A., Gibb, E. L., \& Mumma, M. J. 2002a, Asteroids, Comets, Meteors., ESA SP-500, ESTEC(Noordwijk), 549
Magee-Sauer, K., Mumma, M. J., DiSanti, M. A., \& Dello Russo, N. 2002b, J. Geophys. Res., 107(E11), 5096

Magee-Sauer, K., Mumma, M. J., DiSanti, M. A., et al. 2008, Icarus, 194, 347

Morbidelli, A., Levison, H. F., \& Gomes, R. 2008, in The Solar System beyond Neptune, ed. M. A. Barucci et al. (Tucsom: The University of Arizona Press) 275

Mumma, M. J., DiSanti, M. A., Dello Russo, N., et al. 1996, Science, 194, 347 Mumma, M. J., DiSanti, M. A., Bonev, B. P., et al. 2009, Asteroids, Comets, Meteors., Abstract \#8282, Lunar and Planetary Institute Contribution No 1450, Houston (CD-ROM)

Mumma, M. J., McLean, I. S., DiSanti, M. A., et al. 2001a, ApJ, 546, 1183

Mumma, M. J., Dello Russo, N., DiSanti, M. A., et al. 2001b, Science, 292, 1334

Schloerb, F. P., Kinzel, W. M., Swade, D. A., \& Irvine, W. M. 1986, ApJ, 310, L55

Weaver, H. A., Brooke, T. Y., Chin, G., et al. 1997, Earth Moon and Planets, 78, 71

Table 2. Line identification of detected emissions.

(a) January 28, 2008; $\mathrm{H}_{2} \mathrm{O}$

\begin{tabular}{|c|c|c|c|c|c|}
\hline $\begin{array}{c}\text { Transition } \\
\left(v_{1}^{\prime}, v_{2}^{\prime}, v_{3}^{\prime}\right) J_{K_{a}^{\prime} K_{c}^{\prime}}^{\prime}-\left(v_{1}^{\prime \prime}, v_{2}^{\prime \prime}, v_{3}^{\prime \prime}\right) J_{K_{a}^{\prime \prime} K_{c}^{\prime \prime}}\end{array}$ & $\begin{array}{c}\text { Wavenumber } \\
{\left[\mathrm{cm}^{-1}\right]}\end{array}$ & $\begin{array}{c}\text { Wavelength } \\
{[\AA]} \\
\end{array}$ & $\begin{array}{c}\text { Flux } \\
{\left[\mathrm{W} \mathrm{m}^{-2}\right]}\end{array}$ & $\begin{array}{c}g \text {-factor }{ }^{1} \\
{\left[\mathrm{~W} \text { molecule }^{-1}\right]}\end{array}$ & Atmospheric transmittance \\
\hline$(101) 1_{11}-(001) 2_{02}$ & 3459.53 & 28905.67 & $(8.60 \pm 1.27) \times 10^{-20}$ & $2.48 \times 10^{-27}$ & 0.81 \\
\hline$(101) 4_{31}-(100) 5_{32}$ & 3459.49 & 28905.97 & * & $5.29 \times 10^{-28}$ & 0.81 \\
\hline$(101) 4_{22}-(100) 5_{23}$ & 3456.45 & 28931.44 & $(3.90 \pm 1.08) \times 10^{-20}$ & $4.29 \times 10^{-27}$ & 0.32 \\
\hline$(101) 3_{03}-(001) 3_{12}$ & 3455.43 & 28939.99 & $(1.77 \pm 0.82) \times 10^{-20}$ & $5.65 \times 10^{-28}$ & 0.81 \\
\hline$(101) 2_{11}-(001) 2_{20}$ & 3454.69 & 28946.17 & $(9.28 \pm 0.81) \times 10^{-20}$ & $3.70 \times 10^{-27}$ & 0.80 \\
\hline$(200) 1_{10}-(001) 2_{21}$ & 3453.30 & 28957.81 & $(1.41 \pm 0.08) \times 10^{-19}$ & $7.39 \times 10^{-27}$ & 0.80 \\
\hline$(101) 2_{02}-(100) 3_{21}$ & 3453.15 & 28959.03 & $(1.34 \pm 0.09) \times 10^{-19}$ & $5.62 \times 10^{-27}$ & 0.88 \\
\hline$(200) 1_{10}-(001) 1_{11}$ & 3450.29 & 28983.04 & $(6.10 \pm 0.87) \times 10^{-20}$ & $1.03 \times 10^{-26}$ & 0.21 \\
\hline$(110) 3_{21}-(010) 4_{32}$ & 3449.78 & 28987.36 & $(2.50 \pm 0.77) \times 10^{-20}$ & $6.46 \times 10^{-28}$ & 0.73 \\
\hline$(200) 2_{20}-(001) 2_{21}$ & 3445.89 & 29020.12 & $(3.22 \pm 0.90) \times 10^{-20}$ & $2.11 \times 10^{-27}$ & 0.49 \\
\hline$(200) 2_{12}-(100) 3_{21}$ & 3412.92 & 29300.39 & $(1.10 \pm 0.08) \times 10^{-19}$ & $4.68 \times 10^{-27}$ & 0.80 \\
\hline$(101) 3_{13}-(001) 4_{04}$ & 3411.62 & 29311.61 & $(7.92 \pm 0.66) \times 10^{-20}$ & $3.27 \times 10^{-27}$ & 0.94 \\
\hline$(201) 1_{11}-(200) 1_{10}$ & 3405.42 & 29364.95 & $(5.98 \pm 0.72) \times 10^{-20}$ & $1.78 \times 10^{-27}$ & 0.91 \\
\hline$(201) 2_{21}-(200) 2_{20}$ & 3405.39 & 29365.21 & $*$ & $1.78 \times 10^{-28}$ & 0.90 \\
\hline$(101) 1_{11}-(001) 2_{21}$ & 3404.24 & 29375.11 & $(3.82 \pm 0.77) \times 10^{-20}$ & $1.65 \times 10^{-27}$ & 0.42 \\
\hline$(200) 1_{11}-(001) 2_{12}$ & 3403.23 & 29383.84 & $(1.26 \pm 0.09) \times 10^{-19}$ & $4.29 \times 10^{-27}$ & 0.76 \\
\hline$(200) 1_{01}-(001) 2_{02}$ & 3399.37 & 29417.23 & $(4.01 \pm 0.08) \times 10^{-19}$ & $1.36 \times 10^{-26}$ & 0.82 \\
\hline$(300) 2_{12}-(101) 1_{11}$ & 3389.14 & 29506.05 & $(1.71 \pm 0.63) \times 10^{-20}$ & $2.44 \times 10^{-28}$ & 0.94 \\
\hline$(201) 0_{00}-(200) 1_{01}$ & 3388.77 & 29509.23 & $(8.34 \pm 0.66) \times 10^{-20}$ & $2.65 \times 10^{-27}$ & 0.94 \\
\hline$(101) 4_{04}-(001) 5_{15}$ & 3387.54 & 29519.94 & $(4.28 \pm 0.78) \times 10^{-20}$ & $1.47 \times 10^{-27}$ & 0.89 \\
\hline$(201) 2_{11}-(101) 2_{02}$ & 3385.14 & 29540.66 & $(2.62 \pm 0.94) \times 10^{-20}$ & $7.16 \times 10^{-29}$ & 0.58 \\
\hline$(101) 2_{11}-(001) 3_{22}$ & 3385.14 & 29540.90 & $*$ & $1.60 \times 10^{-27}$ & 0.56 \\
\hline$(200) 2_{12}-(001) 3_{13}$ & 3382.10 & 29567.43 & $(3.79 \pm 0.07) \times 10^{-19}$ & $1.22 \times 10^{-26}$ & 0.89 \\
\hline$(200) 2_{02}-(001) 3_{03}$ & 3378.48 & 29599.08 & $(9.53 \pm 0.76) \times 10^{-20}$ & $3.16 \times 10^{-27}$ & 0.75 \\
\hline$(101) 3_{13}-(100) 4_{22}{ }^{2}$ & 3320.13 & 30119.34 & $(6.44 \pm 0.75) \times 10^{-20}$ & $1.38 \times 10^{-27}$ & 0.97 \\
\hline$(200) 3_{13}-(001) 4_{22}{ }^{2}$ & 3319.47 & 30125.29 & $(5.06 \pm 0.71) \times 10^{-20}$ & $5.10 \times 10^{-28}$ & 0.97 \\
\hline$(101) 3_{22}-(100) 4_{31}^{2}$ & 3319.12 & 30128.50 & $(2.79 \pm 0.57) \times 10^{-20}$ & $1.21 \times 10^{-27}$ & 0.96 \\
\hline$(101) 4_{22}-(001) 5_{33}{ }^{2}$ & 3308.06 & 30229.17 & $(2.63 \pm 0.82) \times 10^{-20}$ & $7.46 \times 10^{-28}$ & 0.68 \\
\hline
\end{tabular}

${ }^{1} T_{\text {rot }}=70 \mathrm{~K} .{ }^{2}$ In setting \#2.

(b) January 28, 2008; HCN $v_{3}$-band

\begin{tabular}{|c|c|c|c|c|c|}
\hline Transition & $\begin{array}{c}\text { Wavenumber } \\
{\left[\mathrm{cm}^{-1}\right]}\end{array}$ & $\begin{array}{c}\text { Wavelength } \\
{[\AA]}\end{array}$ & $\begin{array}{c}\text { Flux } \\
{\left[\mathrm{W} \mathrm{m}^{-2}\right]}\end{array}$ & $\begin{array}{c}g \text {-factor }{ }^{3} \\
{\left[\mathrm{~W} \text { molecule }^{-1}\right]}\end{array}$ & Atmospheric transmittance \\
\hline R6 & 3331.59 & 30015.74 & $(5.08 \pm 1.01) \times 10^{-20}$ & $7.24 \times 10^{-25}$ & 0.97 \\
\hline R5 & 3328.78 & 30041.07 & $(4.22 \pm 0.58) \times 10^{-20}$ & $1.02 \times 10^{-24}$ & 0.94 \\
\hline R4 & 3325.94 & 30066.64 & $(5.77 \pm 1.37) \times 10^{-20}$ & $1.33 \times 10^{-24}$ & 0.90 \\
\hline R3 & 3323.09 & 30092.47 & $(2.68 \pm 0.71) \times 10^{-20}$ & $1.53 \times 10^{-24}$ & 0.59 \\
\hline R2 & 3320.22 & 30118.48 & $(4.71 \pm 0.62) \times 10^{-20}$ & $1.54 \times 10^{-24}$ & 0.97 \\
\hline R1 & 3317.33 & 30144.74 & $(3.43 \pm 2.16) \times 10^{-20}$ & $1.27 \times 10^{-24}$ & 0.86 \\
\hline $\mathrm{P} 2$ & 3305.54 & 30252.21 & $(7.12 \pm 0.73) \times 10^{-20}$ & $1.45 \times 10^{-24}$ & 0.96 \\
\hline P3 & 3302.55 & 30279.21 & $(7.85 \pm 0.89) \times 10^{-20}$ & $1.89 \times 10^{-24}$ & 0.96 \\
\hline $\mathrm{P} 4$ & 3299.53 & 30307.37 & $(7.40 \pm 0.81) \times 10^{-20}$ & $2.02 \times 10^{-24}$ & 0.93 \\
\hline P7 & 3290.35 & 30391.91 & $(3.20 \pm 0.78) \times 10^{-20}$ & $1.16 \times 10^{-24}$ & 0.90 \\
\hline P8 & 3287.25 & 30420.58 & $(2.90 \pm 0.70) \times 10^{-20}$ & $8.01 \times 10^{-25}$ & 0.95 \\
\hline
\end{tabular}

${ }^{3} T_{\text {rot }}=54 \mathrm{~K}$.

Flux values listed in the 4th column are calibrated but not corrected for the telluric absorption. The $g$-factors listed in the 5 th column are calculated for the observational conditions. Field of view of the aperture is $0.2^{\prime \prime} \times \sim 0.8^{\prime \prime}$. The * mark indicates that the line is blended with the line above. 
Table 2. continued.

(c) January 28, 2008; $\mathrm{C}_{2} \mathrm{H}_{2} v_{3}$-band

\begin{tabular}{|c|c|c|c|c|c|}
\hline Transition & $\begin{array}{c}\text { Wavenumber } \\
{\left[\mathrm{cm}^{-1}\right]}\end{array}$ & $\begin{array}{c}\text { Wavelength } \\
{[\AA]}\end{array}$ & $\begin{array}{c}\text { Flux } \\
{\left[\mathrm{W} \mathrm{m}^{-2}\right]}\end{array}$ & $\begin{array}{c}g \text {-factor } \\
{\left[\mathrm{W} \text { molecule }^{-1}\right]}\end{array}$ & Atmospheric transmittance \\
\hline$\overline{\mathrm{R} 3}$ & 3304.17 & 30267.30 & $(1.73 \pm 0.61) \times 10^{-20}$ & $1.03 \times 10^{-24}$ & 0.95 \\
\hline P3 & 3287.76 & 30418.40 & $(3.22 \pm 0.82) \times 10^{-20}$ & $1.05 \times 10^{-24}$ & 0.92 \\
\hline P5 & 3282.99 & 30462.99 & $(2.25 \pm 0.89) \times 10^{-20}$ & $1.27 \times 10^{-24}$ & 0.71 \\
\hline
\end{tabular}

${ }^{4} T_{\text {rot }}=70 \mathrm{~K}$ is assumed.

(d) February 4, 2008; $\mathrm{H}_{2} \mathrm{O}$

\begin{tabular}{|c|c|c|c|c|c|}
\hline $\begin{array}{c}\text { Transition } \\
\left(v_{1}^{\prime}, v_{2}^{\prime}, v_{3}^{\prime}\right) J_{K_{a}^{\prime} K_{c}^{\prime}}^{\prime}-\left(v_{1}^{\prime \prime}, v_{2}^{\prime \prime}, v_{3}^{\prime \prime}\right) J^{\prime \prime}{ }_{K_{a}^{\prime \prime} K_{c}^{\prime \prime}}\end{array}$ & $\begin{array}{c}\text { Wavenumber } \\
{\left[\mathrm{cm}^{-1}\right]}\end{array}$ & $\begin{array}{c}\text { Wavelength } \\
{[\AA]}\end{array}$ & $\begin{array}{c}\text { Flux } \\
{\left[\mathrm{W} \mathrm{m}^{-2}\right]}\end{array}$ & $\begin{array}{c}\text {-factor }{ }^{5} \\
{\left[\mathrm{~W} \text { molecule }^{-1}\right]}\end{array}$ & Atmospheric transmittance \\
\hline$(201) 1_{11}-(200) 1_{10}$ & 3405.42 & 29364.95 & $(4.07 \pm 0.78) \times 10^{-20}$ & $1.81 \times 10^{-27}$ & 0.85 \\
\hline$(201) 2_{21}-(200) 2_{20}$ & 3405.39 & 29365.21 & $*$ & $1.58 \times 10^{-28}$ & 0.82 \\
\hline$(200) 1_{11}-(001) 2_{12}$ & 3403.23 & 29383.84 & $(6.84 \pm 0.77) \times 10^{-20}$ & $4.63 \times 10^{-27}$ & 0.64 \\
\hline$(200) 1_{01}-(001) 2_{02}$ & 3399.37 & 29417.23 & $(1.98 \pm 0.06) \times 10^{-19}$ & $1.37 \times 10^{-26}$ & 0.74 \\
\hline$(200) 2_{21}-(100) 3_{30}$ & 3394.08 & 29463.10 & $(1.00 \pm 0.06) \times 10^{-19}$ & $1.10 \times 10^{-26}$ & 0.63 \\
\hline$(200) 4_{14}-(001) 4_{13}$ & 3390.04 & 29498.19 & $(3.25 \pm 0.62) \times 10^{-20}$ & $2.08 \times 10^{-28}$ & 0.74 \\
\hline$(101) 2_{12}-(100) 3_{31}$ & 3390.02 & 29498.38 & $*$ & $1.47 \times 10^{-27}$ & 0.79 \\
\hline$(201) 0_{00}-(200) 1_{01}$ & 3388.77 & 29509.23 & $(3.68 \pm 0.72) \times 10^{-20}$ & $2.81 \times 10^{-27}$ & 0.90 \\
\hline$(200) 2_{12}-(001) 3_{13}$ & 3382.10 & 29567.43 & $(1.63 \pm 0.05) \times 10^{-19}$ & $1.25 \times 10^{-26}$ & 0.86 \\
\hline$(200) 2_{02}-(001) 3_{03}$ & 3378.48 & 29599.08 & $(3.81 \pm 0.53) \times 10^{-20}$ & $3.09 \times 10^{-27}$ & 0.77 \\
\hline$(200) 2_{21}-(001) 3_{22}$ & 3372.76 & 29649.35 & $(9.25 \pm 0.53) \times 10^{-20}$ & $7.13 \times 10^{-27}$ & 0.89 \\
\hline$(210) 2_{21}-(110) 3_{30}$ & 3361.03 & 29752.74 & $(2.45 \pm 0.55) \times 10^{-20}$ & $5.19 \times 10^{-28}$ & 0.66 \\
\hline$(200) 3_{13}-(001) 4_{14}$ & 3360.99 & 29753.14 & $*$ & $1.77 \times 10^{-27}$ & 0.62 \\
\hline$(200) 3_{03}-(001) 4_{04}$ & 3358.92 & 29771.45 & $(8.64 \pm 0.61) \times 10^{-20}$ & $4.83 \times 10^{-27}$ & 0.78 \\
\hline$(201) 2_{02}-(200) 3_{03}$ & 3346.99 & 29877.58 & $(6.73 \pm 0.63) \times 10^{-20}$ & $2.60 \times 10^{-27}$ & 0.94 \\
\hline$(200) 3_{12}-(001) 4_{13}$ & 3341.17 & 29929.64 & $(2.94 \pm 0.54) \times 10^{-20}$ & $2.22 \times 10^{-27}$ & 0.90 \\
\hline$(200) 4_{14}-(001) 5_{15}$ & 3340.95 & 29931.63 & $(2.71 \pm 0.53) \times 10^{-20}$ & $2.13 \times 10^{-27}$ & 0.88 \\
\hline$(201) 3_{13}-(200) 4_{14}$ & 3329.42 & 30035.28 & $(1.89 \pm 0.66) \times 10^{-20}$ & $1.07 \times 10^{-27}$ & 0.85 \\
\hline
\end{tabular}

(e) February 4, 2008; $\mathrm{CH}_{4} v_{3}$-band

\begin{tabular}{cccccc}
\hline \hline Transition & $\begin{array}{c}\text { Wavenumber } \\
{\left[\mathrm{cm}^{-1}\right]}\end{array}$ & $\begin{array}{c}\text { Wavelength } \\
{[\AA]}\end{array}$ & $\begin{array}{c}\text { Flux } \\
{\left[\mathrm{W} \mathrm{m} \mathrm{m}^{-2}\right]}\end{array}$ & $\begin{array}{c}g \text {-factor } \\
{[\mathrm{W} \mathrm{molecule}}\end{array}$ & Atmospheric transmittance \\
\hline R1 & 3038.50 & 32913.67 & $(2.03 \pm 0.78) \times 10^{-20}$ & $1.20 \times 10^{-24}$ & 0.32 \\
R0 & 3028.75 & 33019.58 & $(3.44 \pm 0.76) \times 10^{-20}$ & $1.46 \times 10^{-24}$ & 0.27 \\
\hline 6
\end{tabular}

${ }^{6} T_{\text {rot }}=70 \mathrm{~K}$ is assumed.

(f) February 4, 2008; $\mathrm{C}_{2} \mathrm{H}_{6} v_{7}$-band

\begin{tabular}{|c|c|c|c|c|c|}
\hline Transition & $\begin{array}{c}\text { Wavenumber } \\
{\left[\mathrm{cm}^{-1}\right]}\end{array}$ & $\begin{array}{c}\text { Wavelength } \\
[\AA]]\end{array}$ & $\begin{array}{c}\text { Flux } \\
{\left[\mathrm{W} \mathrm{m}^{-2}\right]}\end{array}$ & $\begin{array}{c}g \text {-factor }{ }^{7} \\
{\left[\mathrm{~W} \text { molecule }^{-1}\right]}\end{array}$ & Atmospheric transmittance \\
\hline${ }^{R} \mathrm{Q}_{0}$ & 2986.73 & 33481.43 & $(4.23 \pm 0.60) \times 10^{-20}$ & $2.10 \times 10^{-24}$ & 0.91 \\
\hline${ }^{P} \mathrm{Q}_{1}$ & 2983.38 & 33519.03 & $(4.51 \pm 0.60) \times 10^{-20}$ & $1.89 \times 10^{-24}$ & 0.94 \\
\hline${ }^{P} \mathrm{Q}_{2}$ & 2980.07 & 33556.26 & $(5.01 \pm 1.01) \times 10^{-20}$ & $1.71 \times 10^{-24}$ & 0.79 \\
\hline${ }^{P} \mathrm{Q}_{3}$ & 2976.77 & 33593.46 & $(2.58 \pm 0.71) \times 10^{-20}$ & $1.22 \times 10^{-24}$ & 0.91 \\
\hline
\end{tabular}

${ }^{7} T_{\text {rot }}=70 \mathrm{~K}$ is assumed, Dello Russo et al. (2001).

(g) February 4, 2008; $\mathrm{CH}_{3} \mathrm{OH} v_{2}$-band

\begin{tabular}{|c|c|c|c|c|c|}
\hline Transition & $\begin{array}{c}\text { Wavenumber } \\
{\left[\mathrm{cm}^{-1}\right]}\end{array}$ & $\begin{array}{c}\text { Wavelength } \\
{[\AA]}\end{array}$ & $\begin{array}{c}\text { Flux } \\
{\left[\mathrm{W} \mathrm{m}^{-2}\right]}\end{array}$ & $\begin{array}{c}g \text {-factor } \\
{\left[\mathrm{W} \text { molecule }^{-1}\right]}\end{array}$ & "Atmospheric transmittance \\
\hline & 3001.10 & 33323.83 & $(4.80 \pm 0.88) \times 10^{-20}$ & $2.86 \times 10^{-25}$ & 0.95 \\
\hline & 3001.04 & 33324.49 & * & & 0.94 \\
\hline & 2997.16 & 33367.63 & $(5.38 \pm 0.70) \times 10^{-20}$ & & 0.89 \\
\hline & 2997.15 & 33367.75 & * & & 0.85 \\
\hline
\end{tabular}

${ }^{8}$ The $g$-factor of the $v_{2}$ methanol line listed here is derived from the $g$-factor of the methanol $v_{3}$-band $Q$-branch by comparing the intensities of these lines in cometary spectra (see text). The $g$-factor of the methanol $v_{3}$-band $Q$-branch is taken equal to $5.80 \times 10^{-25}$ [W molecule ${ }^{-1}$ ] at $T_{\text {rot }}=70 \mathrm{~K}$ (DiSanti, private comm.). 